\title{
Dichotomy of lay people and health professionals perception of physical activity is a challenge for activity education and promotion within primary health care - a qualitative study
}

\author{
Dorota Cianciara' ${ }^{1,2, A-F \oplus}$, Larysa Sugay ${ }^{1, A, D-E \oplus}{ }^{\oplus}$ Katarzyna Lewtak $^{1, A, D-E \oplus}{ }^{\circ}$, Ewa Urban ${ }^{1, A-B, D \oplus}$, \\ Maria Piotrowicz, ${ }^{1, \mathrm{~B}-\mathrm{D} \oplus}$, Małgorzata Gajewska ${ }^{1, \mathrm{~B}-\mathrm{D} \oplus}$, Paloma Cuchí, ${ }^{3, \mathrm{~A}, \mathrm{E}-\mathrm{F} \oplus}$ \\ ${ }^{1}$ Department of Health Promotion and Prevention of Chronic Diseases, National Institute of Public Health-National \\ Institute of Hygiene, Warsaw, Poland \\ ${ }^{2}$ Department of Epidemiology and Health Promotion, School of Public Health, Centre of Postgraduate Medical \\ Education, Warsaw, Poland \\ ${ }^{3}$ WHO Country Office, Warsaw, Poland \\ A - Research concept and design, B - Collection and/or assembly of data, C - Data analysis and interpretation, \\ $D$ - Writing the article, E - Critical revision of the article, F- Final approval of article
}

Cianciara D, Sugay L, Lewtak K, Urban E, Piotrowicz M, Gajewska M, Cuchí P. Dichotomy of lay people and health professionals perception of physical activity is a challenge for activity education and promotion within primary health care - a qualitative study. Ann Agric Environ Med. 2021; 28(4): 645-653. doi: 10.26444/aaem/131555

\begin{abstract}
Ibstract
Introduction. According to the WHO, healthy adults aged 18-64 should perform at least 150 min of moderate-intensity aerobic physical activity (PA), or at least 75 min of vigorous-intensity PA, throughout the week, or an equivalent combination of moderate and vigorous activity. These recommendations should be promoted and involved in primary health care (PHC) staff daily practice. Tailoring the education message depends on peoples' perspective on PA, but in Poland there is no research on the subject.

Objective. The aim of the study was to explore and compare the perception of lay people (LP) and health professionals (HP) of PA to find similarities and differences in their perspective - as this may have an impact on PHC-based education on PA (favourable or unfavourable).

Materials and methods. Six mini FGls were carried out. Research sample consisted of 16 LP from urban settings and 10 HP (doctors, nurses).

Results. LP and HP appreciated PA as important and considerably controllable health determinant. LP attributed the main gains of PA to psycho-social benefits, and HP strictly to diseases risk reduction. Both groups had difficulties in defining PA and doubts abounded about PA and exercise. Optimal dose (volume) of PA was generally unclear and the WHO recommendation were unknown. HP seemed to be more eager than LP to appreciate simple forms of PA, e.g. walking. Barriers to PA perceived by LP were described in terms of 'real life' factors (sportswear, access, job), and HP mostly by cognition (knowing, judging) and social status. LP preferred positive, rewarding motivation for PA, but HP one that was negative and fear-based.

Conclusions. Referring to activity, LP and HP were like travellers in parallel universes. This created challenges in PHC-based education. Some suggestion for PA education were given. More qualitative and quantitative research are needed.
\end{abstract}

\section{Key words}

Physical activity, focus group, lay people, health professionals, primary health care, WHO recommendation, Poland

\section{Abbreviations}

PA - Physical Activity, WHO - World Health Organization, PHC - primary health care, NCDs - non-communicable diseases, DINKS - double income, no kids, FGIs - focus group interviews, NIPH-NIH - National Institute of Public Health-National Institute of Hygiene, GDPR - General Data Protection Regulation, IEC - information, education, communication, IDI - InDepth Interview

\section{INTRODUCTION}

There is much evidence indicating that insufficient physical activity (PA) is a risk factor for chronic diseases, including depression, and has an adverse effect on the quality of life and mental well-being. Insufficient PA is one of the modifiable

Address for correspondence: Katarzyna Lewtak, Department of Health Promotion and Prevention of Chronic Diseases, National Institute of Public Health-National Institute of Hygiene, Chocimska 24, 00-791 Warsaw, Poland

E-mail:klewtak@pzh.gov.pl

Received: 01.09.2020; accepted: 04.12.2020; first published: 30.12 .2020 risk factors. Early approaches aimed at increasing PA were focused on individuals and on motivating them to change behaviour to be fit and prevent some diseases. Over time, the fitness culture has grown and become highly individualized and commercialized, which excluded many people, especially those with a low-income, from certain PA practices. Where evidence has shown that the individual approach is insufficient to achieve wide-scaled PA there has been a change towards public health-oriented recommendations $[1,2,3]$. Among the most widely-known of this new and evidencebased approach to PA was issued in 1995 by the US Centers for 
Disease Control and Prevention and the American College of Sports Medicine [4]. This evolution was rooted in the socioecological model of health and therefore the importance of various environmental and social factors were stressed, as well as the need for multi-sectoral and systemic actions $[5,6]$. It was also recognized that PA covers four broad areas of life, including professional, home-related (work at home, in the yard, in the garden, childcare), transport (cycling, walking) and leisure time (recreation, sport, exercise and hobby).

On the international level, the WHO has made various appeals, guidelines and recommendations on PA [7, 8]. They were addressed to policy makers as well as to health professionals and other stakeholders to take actions aimed at increasing activity in populations. This was followed by recommendations at the national level. In 2012, as many as 32 countries out of $53 \mathrm{WHO} /$ Europe did not have official recommendations [9]. In 2018, an official document in this regard was located in 23 of the 28 EU Member States [10]. In Poland, the document 'The national recommendations for pro-health PA' was elaborated by the Jerzy Kukuczka Academy of Physical Education in Katowice in 2018 [11], but its dissemination and implementation seem to be limited. Further steps are needed for the recommendations to enter into force at community level [12]. Action plans addressed directly to the specific public, such as promotion of the recommendations [13] and communication channels with selected recipients, tailoring messages and education, should be created $[14,15,16]$. Such activities have to be the subject of planning and evaluation. WHO/Europe recommend implementing this education as the core task for PHC staff.

Current WHO recommendations for healthy adults aged 18-64 should be covered by moderate aerobic PA (e.g. brisk walking or cycling) for at least 150 minutes (2.5 hours), or by intensive activity (e.g. running) for at least 75 minutes a week, or combined moderate and intensive activity, according to individual preferences [17]. A dose of activity identical to WHO is recommended in the $\mathrm{UK}$, but those recommendations are more specific with regard to some diseases [18]. On the other hand, recommendations from the USA and Australia suggest that moderate activity may be increased even up to 300 minutes (5 hours) or intensive activity up to 150 minutes (2.5 hours) per week $[19,20]$. Polish recommendations from 2018 are consistent with the WHO but we can also find extended recommendations. It should be emphasized that the 150 minutes weekly dose (or its equivalent) for people aged $18+$ has been adopted by the WHO as an indicator of sufficient PA within the Global NCDs Action Plan 2013-2020 [21]. This threshold is used in various studies assessing the level of activity. For example, in the study by Guthold et al., it was found that in 2016 the global age-standardized prevalence of insufficient PA was 27.5\%, and between 2001-2016 the levels of insufficient activity were stable. According to the authors, such configuration makes achievement of the WHO global goal impossible, i.e. $10 \%$ relative reduction in insufficient PA [22]. In the above mentioned study, it was estimated that the level of insufficient PA in Poland for both genders was 32.5\% (95\% CI 25.3-40.5), which contradicts the results of the study commissioned by the Polish Ministry of Sport and Tourism. According to that study, in 2017 and 2018, the majority of Poles aged 15-69 met the WHO criteria for the required level of activity, taking into account all types of activity $(88.0 \%, 83.8 \%$, respectively) [23]. The WHO criteria were also used in other Polish studies [24, 25], but the question arise, whether there is a sense of measuring compliance with regard to unknown recommendations. At present, there are more and more scientific papers contesting the population effectiveness of these recommendations. Some studies clearly show that there is no linear correlation between an increase of activity and decrease of mortality [26, 27], although it is easy to observe an increased tendency for statements that 'every step counts' [28].

The research field related to PA has grown significantly in recent years, although there are still many answers being sought. It is known, for example, that despite the growing number of studies regarding the effectiveness of interventions, and even systematic reviews on this subject, there is still a lack of research on the effects of upstream approaches to PA, such as environmental and policy interventions [29]. In the literature prevail articles describing the importance of activity [30]. Relatively few articles address knowledge and awareness about the existence of recommendations regarding PA and dose (volume) of activity [31, 32, 33]. The least represented are papers on the way of PA interpretation given by people, its definition, meaning or role for an individual person or entire communities. Meanwhile, recognition of the public perception of PA is crucial for planning the PA promotion for all adults. The recognition of the health professionals perception of PA is also important as the WHO/Europe strategy stress the role of $\mathrm{PHC}$ staff in activity promotion. $[8,34,35]$.

\section{OBJECTIVES}

The aim of the study was to explore and compare the perception of lay people and health professionals of $\mathrm{PA}$, in order to find similarities and differences in their perspectives - at this may have impact on PHC-based education on PA (favourable or unfavourable).

\section{MATERIALS AND METHOD}

The participants of the study were divided in two groups: 'regular people', who were not health or sport/fitness professionals (thereafter referred to as lay people - LP) and doctors or nurses (referred to as health professionals - HP). Participants went through the selection process in which they were recruited by phone, and then by completing a questionnaire. Purposive and maximum-variation sampling were used [36].

The criteria for LP inclusion in the study were: (a) place of residence (city including neighbourhood - over 500,000 residents, town including neighbourhood - below 30,000 residents), (b) residents of various city districts (centre: apartment blocks, suburbs: houses with gardens), (c) selfassessment of PA (active, inactive), (d) both genders, (e) age 25-45, (f) being employed, (g) different levels of education (vocational, secondary, higher), (h) persons with family and children, single, and DINKS. Exclusion criteria were working in the health/sport/fitness sector and recent participation in a similar interview. A total of 16 lay people took part in the study, two women and two men in each interview.

The criteria for including HP were: (a) profession (doctor, nurse), (b) work at PHC, (c) both genders, (d) seniority 
longer than a year, (e) place of residence (city, including neighbourhood - over 500,000 residents). Exclusion criterion: recent participation in FGI. Five doctors (one men, four women) were included in the study and five nurses (women only). Two of the selected doctors had work experience of $11-$ 21 years, and three - over 21 years. Two nurses had seniority up to 10 years, and three - over 21 years.

The following research questions were stated:

1) How is PA regarded and interpreted?

2) Why and how PA is undertaken?

3) What actions should be recommended and undertaken to motivate urban adult dwellers to increase PA?

Six mini-FGIs were conducted according to the following scheme:

\begin{tabular}{lccccc}
\hline \multirow{2}{*}{ Location } & \multicolumn{2}{c}{ LP } & \multicolumn{2}{c}{ HP } \\
\cline { 2 - 5 } & Physically active & Physically inactive & Doctors & Nurses \\
\hline Warsaw & $\mathrm{X}$ & $\mathrm{X}$ & $\mathrm{X}$ & $\mathrm{X}$ \\
\hline Łowicz & $\mathrm{X}$ & $\mathrm{X}$ & & \\
\hline
\end{tabular}

In this scheme, Warsaw represents a large city, and Łowicz a relatively small town with socio-demographic characteristics and infrastructure (i.e. recruiters, facilities) relevant to carry out FGIs, as well as other qualitative research.

A team of researchers from NIPH-NIH designed the study and contracted a research agency to carry out mini-FGIs. The 4P Research Mix Company, under the supervision of the study authors, conducted the recruitment, interviews and recordings. The interviews were conducted on 3-4 December 2019, were audio recorded and lasted about 2 hours each. Personal data protection requirements were applied in accordance with the GDPR (Polish - RODO). After making a standard transcription the researchers analyzed the transcripts, applying investigator triangulation [37], coded, ordered and selected themes. The final scope of analysis focused on the following variables:

\begin{tabular}{|c|c|c|c|c|}
\hline \multirow{2}{*}{$\begin{array}{l}\text { Research } \\
\text { question }\end{array}$} & \multirow[b]{2}{*}{ Themes } & \multicolumn{3}{|c|}{ Perception / perspective } \\
\hline & & $\mathrm{LP}$ & HP & $\begin{array}{c}\text { HP on LP } \\
\text { perspective }\end{array}$ \\
\hline \multirow{3}{*}{1} & Role and significance of PA & $x$ & $\mathrm{x}$ & $x$ \\
\hline & Definition of PA & $\mathrm{x}$ & $\mathrm{x}$ & \\
\hline & Image of an active person & $x$ & $\mathrm{X}$ & \\
\hline \multirow{2}{*}{2} & Benefits of PA & $x$ & $\mathrm{x}$ & \\
\hline & Optimal dose of PA & $x$ & $\mathrm{X}$ & \\
\hline \multirow{2}{*}{3} & Barriers to PA, social structural factors & $x$ & $\mathrm{x}$ & \\
\hline & Drivers, IEC, PHC role & $x$ & $x$ & \\
\hline
\end{tabular}

The quality of the analysis and description was verified using the check-list described by K.Malterud [38].

Quotes of participants' statements were presented in Tables 1 and 2 . The following notations were used: for LP gender and activity level (woman - W, men - M, active - A, inactive - I), for HP profession (doctor - MD, nurse - N), and for doctors additionally gender (W, M). Some statements have been shortened.

\section{RESULTS}

Role and significance. LP were asked to indicate factors determining health. They analyzed various influencing aspects such as family, climatic or genetic factors. FGIs participants discussed the circumstances and the factors' impact and finally decided that determinants should be assessed according to two criteria: having personal control ('it depends on me') and positive impact on health. Both active and inactive participants admitted that the best option for health is 'do no harm' (e.g. do not smoke or drink alcohol excessively), but there was disagreement among participants regarding the degree of control over the above-mentioned factors: they unanimously recognized that PA has great importance for health (although with a risk of injury or infection, e.g. in the swimming pool), and it is a factor that can be controlled (Fig. 1). They questioned whether PA or

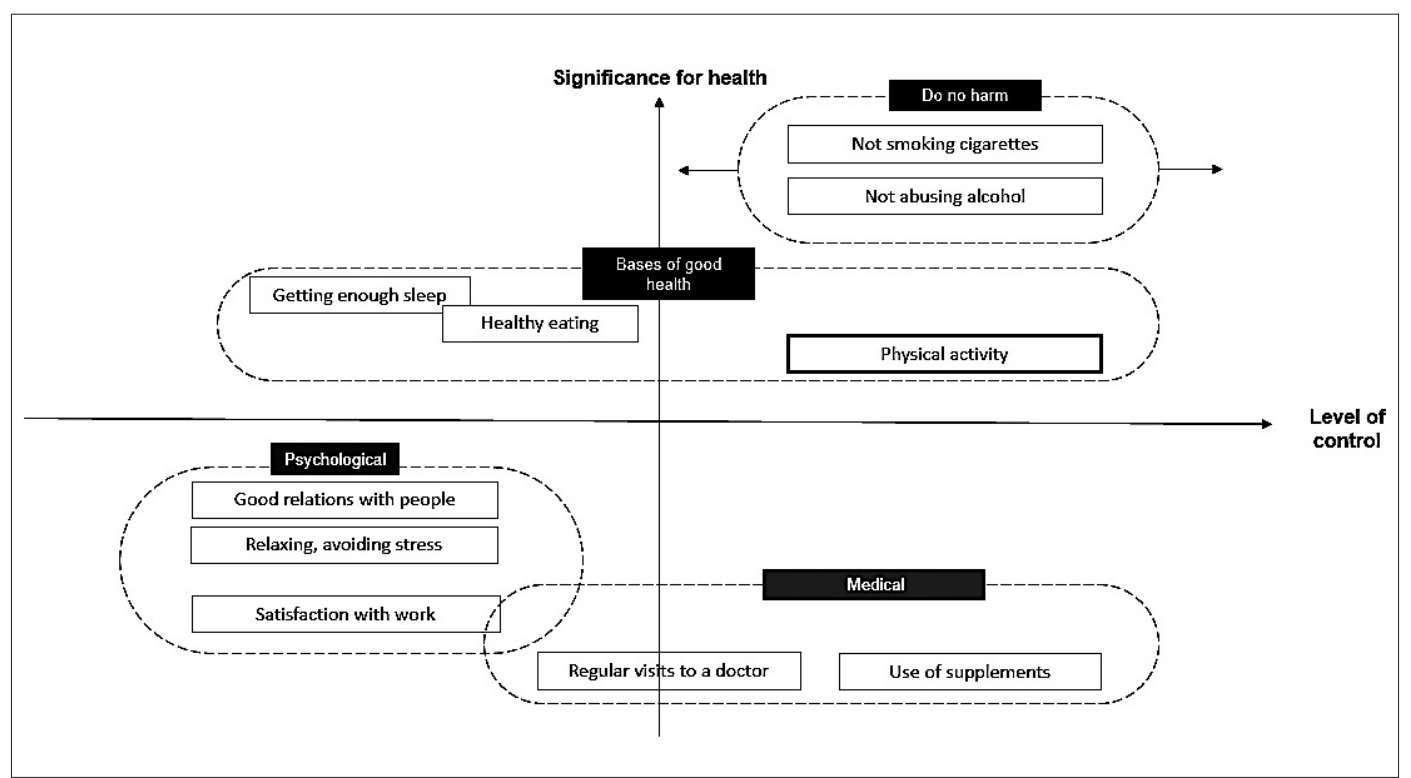

Figure 1. Lay opinion on health determinants lined up by significance for health and level of individual control. Source: own elaboration 
healthy nutrition was more important (Tab.1; quotes 1,2). As a result, healthy eating was placed lower in the determinants ranking because it is more difficult to control. LP did not attach much importance to the role of medical factors (Tab. 1;3).

HP lined up the health determinants in the same order as lay people, but with the strongest emphasis on the role of PA (Tab.2; quote 1). However, when HP were asked how would the ranking of determinants look if made by people/patients, they placed the use of dietary supplements and medical check-ups on the first place. Many of the HP questioned the possibility of self-control over PA (Tab.2; 2).

Definition. For LP, the basic distinctive feature of PA was movement or mobility. For the active people it was fun, a reward, fascination, way of life, ritual or custom (Tab.1; 4,5). Among other features of activity, all LP mentioned extra activities/tasks, planning, preparation, organization and regularity (Tab.1; 6,7); voluntary participation, pleasure and relaxation were crucial (Tab.1; 8-10). Also of importance were the effort, condition, form, efficiency, and deliberate development of the specific skill (e.g. style of swimming) (Tab.1; 11). Only some LP included activities related to work (e.g. cycling), household (e.g. gardening) or raising children into the definition of PA (Tab.1; 12). To PA they did not include neither competitive sport, or professional work, especially hard physical work.

HP also had difficulties defining PA, and emphasized the regularity, purpose or place of the movement (Tab. 2;3-5). They distinguished sport and PA (Tab. 2; 6).

An image of a physically active person. Applying the portrait technique, LP described an active person. They used stereotypical associations regarding the appearance of the body and figure, i.e. active people are slim and healthy, but inactive people are obese or plump, and unhealthy. They mostly associated intensive PA with high social status, i.e. profession and career (a career-obsessed head of the company), outfit (jacket or coat), body posture (crossed arms), a well-groomed attractive appearance. To the inactive people were included a stereotyped housewife or blue-collar worker, someone who is always tired with an unkempt appearance, lies on the sofa, does not shun drugs or grilled fatty food. Other examples of the inactive person were internet bum, game maniac or eccentric, who smokes a 'blunt'l and sleeps a lot (LP quotes).

HP made a strictly professional diagnosis based on the results of physical check-ups and by the appearance of the people. They additionally used a certain mental pattern and described active people as satisfied, financially established, motivated, better educated, intellectual and responsible. Those who were inactive were called 'an alcohol-beer group' $(\mathrm{MD}, \mathrm{M})$ with a poor appearance.

Benefits. LP mainly discussed the gains of PA which were not linked to reducing the risk of diseases or improving physical health (Tab.1; 13). They highly valued good looks, a well-proportioned figure, body flexibility, and 'a soldier's gait' $(\mathrm{M}, \mathrm{A})$. As the basic benefits they considered aspects of mental

1 A 'blunt' is a hollowed-out, cheap cigar filled with cannabis and rolled with the tobacco leaf 'wrap'. A 'blunt' differs from a 'joint' which uses cigarette rolling papers. and spiritual well-being, such as mood boosting, detachment from everyday life, stress reducing, mind clearing, and lack of negative thoughts (Tab.1; 14-16). They also associated activity with such social benefits as meeting 'cool' people and making contacts.

For doctors, the key benefits of PA were the absence of enumerated diseases, weight reduction and improvement of numerous physiological and biochemical parameters, whereas nurses more often mentioned psycho-social benefits, including well-being, self-discipline, mobilization, and 'absolution' (Tab.2; 7).

Optimal dose. All LP stated that they had not heard about the recommendations regarding the type or duration of PA. In trying to define activity frames they gave different standards, emphasizing many variables (Tab.1; 17,18). Some participants had a very comprehensive opinion of optimal dose (Tab.1; 19). The main points of this statement are that this intense plan of PA was presented by a woman who classified herself as inactive person, although she lives in the suburbs, walks a considerable distance to public transport, and works regularly in her garden.

Doctors mentioned the rule ' $3 \times 30 \times 130$ ' (i.e. exercises 3 times a week for 30 minutes, with a heart rate about 130 beats) and 10,000 steps a day, which corresponds to 6-7 km, plus something more intensive twice a week, e.g. running. They reiterated that the dose of PA depends on many factors, including individual movement difficulties and pain sensation. Compared to LP, they endorsed simple (e.g. walking) and diverse forms of movement (Tab. 2; quote 8). They expressed doubts as to the meaning of the optimal dose as this follow fashions (Tab. 2; 9). Nurses also referred to the rule ' $3 \times 30 \times 130$ ' and appreciated various forms of movement, such as a daily walking to and from work.

Barriers, social structural factors. Inactive LP pointed out that there are some 'real life' obstacles in practicing PA. These factors included the need of having the 'right' clothes or reaching the 'right' place, lack of company, being in a relationship, moving to a new house, changing jobs, and everyday problems. As a result of existing obstacles, 'material fatigue' occurs (Tab. 1, 20,21). The risk of stigmatization or shame were considered as additional barriers to PA (Tab. 1, $22,23)$. Active people did not seem to be constrained by 'real life' (family, job, etc.).

According to HP, the dominant barriers in performing PA are people's lack of knowledge and thinking that it's not worth it, followed by lack of time, fatigue, dejection, and movement difficulties or pain. In contrast to LP opinions, numerous statements by HP referred to the relationship between PA and demographic or socio-economic status, and cognition processes, such as knowing and judging. HP pointed out the importance of age, gender, level of education and place of work (Tab. 2; 10-14). Professionals noted the relationship between PA and social roles, especially the role of an employed mother (Tab. 2; 15).

Drivers, IEC, PHC role. LP asked about motivation to PA, referred to internal and external drivers, stating that a lot depends on the personal attitude (Tab. 1;24). As an external driver, they referred to some material gains, such as collecting coupons or stickers, with the possibility to exchange them for sports gadgets (e.g. water bottle or bag). 
LP more often talked about the quantity but not the quality of available information, and expressed that there are a lot of it (Tab. 1; 25-27). Comments after watching various TV advertisement showing that body positivity messages (e.g. British ad 'This girl can') would have greater impact on them than those appealing to fear. Some participants said that a conversation with $\mathrm{HP}$ can be effective in motivating people to $\mathrm{PA}$, in the case where it would be really specific and adjusted to the person's situation (Tab. 1; 28,29). Other participants believed that at present the role of HP in this regard is negligible, and no one can expect any changes (Tab. 1;30-32).

Doctors agreed that the fear appeals are an effective driving force for PA (Tab. 2; 16). Some nurses were willing to motivate their patients by emphasising and promoting the benefits of PA. HP also considered that there is a high availability of information (Tab. 2; 17,18). Opinions about their own role in raising awareness and motivation among patients were divided into pros and cons (Tab. 2; 19-22). They declared that there is a need to raise this topic during the encounter with patients, but they do not have time for it, their authority is heavily strained and they do not really know whose responsibility it is - the doctor or the nurse. The discussion showed that if they educate their patients, it looks more like a warning than a motivation. This education is far from being systematic or organized, but is an ad hoc activity on seeing a patient with visible signs of sedentarism. Doctors declared that motivation should take place mainly through personal trainers, media or infrastructure development (bicycle paths, facilities with easy access, cheap tickets or free admission). As for themselves, they claimed lack of support materials, such as methodological guides (e.g. how to start and conduct a conversation with patients, caloric expenditure charts, etc.), and mobile applications. Nurses had greater readiness to conduct the patients education, but expected support materials (e.g. activity record books similar to those for blood pressure monitoring) and substantive support in the form of training. (Tab. 2; 23).

\section{DISCUSSION}

Most studies on PA are quantitative and answer the questions of what, how much, where, when and how often. The results of these studies focued on identifying demographic or cognitive correlates with PA (factors associated with activity), such as, age, gender, health or self-efficacy. Qualitative studies, including FGIs, are recommended for understanding and interpreting quantitative data, because they help to answer the questions what, which way, why and what for. Also qualitative studies help in the designation of PA determinants (factors with a causal relationship). Currently, qualitative research is becoming increasingly popular in health research.

This is the first qualitative study in Poland to assess how lay people, who are not health or sport/fitness professionals, perceive PA. Simultaneously, PA perception among HP was explored. The research design was motivated by an effort to assess the potential of PHC-based PA education and promotion in urban settings. The role and significance of physical activity, its definition, image of an active person, benefits of activity, optimal dose, barriers and drivers to activity were explored. These aspects are similar to KAP (knowledge-attitudes-practice) framework. Nevertheless, the presented study did not refer to this framework which is used for surveys carried out in non-experimental quantitative social research.

In the current analysis, no distinctive and unequivocal differences were found in the opinions of active and inactive lay people. With its small sample size, the study was not designed for this, and needs to be explored further.

Lay people (LP) were fully aware that being active brings a lot of benefits for health, much more than supplements or medical check-ups, and that it more-or-less depends on themselves. This suggests that knowledge and attitude, related to PA are sufficient for behavioural change, and there is no need to constantly repeat and emphasize health benefits in IEC aimed at increasing activity. By contrast, HP were inclined to question both the cognitive processes of LP and the possibilities of taking PA.

Neither lay people nor professionals were able to define PA precisely. LP most often mixed activity with exercise - 'a subset of physical activity that is planned, structured, repetitive and has as a final or an intermediate objective the improvement or maintenance of physical fitness' [39, 40, 41]. In their reasoning, even $24 \mathrm{~km}$ daily cycling to-andfrom work does not deserve to be called high PA, because of its association with their duties; likewise, regular home gardening was also not considered as a physical activity. However, lay people excluded sport from PA. On the other hand, professionals seemed to accept any form of movement (walking for example), if it is regular and in the fresh air. No one mentioned the amount of PA recommended by national authorities or the WHO, nor do they refer to any professional terms. Thus, physical activity and its characteristics, were perceived and interpreted aside these recommendations. Therefore, meaning and interpretation are individual and depend on many factors, as shown in many studies, for example, carried out among African-American and American-Indian [42] and Swedish women [43]. Such differences should be taken into account in the design of future studies and IEC efforts. There is a particularly high necessity to explain the difference between PA, exercises and sport which will facilitate PA promotion.

The generalization regarding the image of active people was common for lay people and professionals alike. The stereotype in which the active person is assigned to a higher socio-economic status was highlighted in their answers. This creates many challenges, including ethical challenges (e.g. victim blaming) for future IEC actions. Stereotyping and stigmatization should be avoided in accordance with public health ethics. At the same time, active persons at their selfassessment of PA used emoji with smiling, grinning or heartshaped-eyes faces, and words describing self-satisfaction and joy. However, taking into account that the prevalence of over-estimation concerns about half of the population [44], it is not known whether the high estimation of those participants was justified. Inactive people chose emoji with grimacing or disappointed face, expressing embarrassment, sadness and discomfort, which showed that inactive people did not seek excuses, but rather felt guilty. Therefore, no cognitive dissonance was observed, which would lead to negation of PA.

Differences between the lay people and professionals observed in this study, allow the advancing of a thesis that these groups are like 'travellers in parallel universes'. This can be explained in two ways. First, it could be another example of the existence of lay concepts of health as a non-professional 
Table 1. Lay people quotes by the theme

\begin{tabular}{|c|c|}
\hline \multicolumn{2}{|r|}{ Role, relation to healthy nutrition and significance of PA } \\
\hline 1 & Healthy nutrition will be a priority for me. I wouldn't even have to do any physical activity in my life because I simply wouldn't need it if I had eaten well (M, I) \\
\hline 2 & You will not have the strength and willingness [for any activity] unless you eat something solid (W, A) \\
\hline 3 & The use of supplements and regular visits to a doctor I would place at the very end [of significance for health] (W, A) \\
\hline \multicolumn{2}{|r|}{ Definition of PA } \\
\hline 4 & It's a habit, like brushing my teeth $(\mathrm{W}, \mathrm{A})$ \\
\hline 5 & It happened that I could not imagine myself not going to training $(M, A)$ \\
\hline 6 & It is like a routine, for example, I change my outfit, then there is a warm-up. Well, then I have to take a shower (M, I) \\
\hline 7 & It's just kind of preparation, labelling, following some ritual, the repetition and regularity $(\mathrm{W}, \mathrm{I})$ \\
\hline 8 & For me, [jumping jacks] is not PA, it is something that I have to do. That's what the doctor and the physiotherapist forced me to do (W, A) \\
\hline 9 & The act of simple walking is hard to be perceived as physical activity, no matter how slow or fast we are doing it $(\mathrm{M}, \mathrm{l})$ \\
\hline 10 & $\begin{array}{l}\text { My work requires me to squat, stand, bend down, pull these pallets with weights, etc. But it doesn't give me real satisfaction, because I would prefer to do this } \\
\text { activity outside work, as a form of relaxation }(\mathrm{W}, \mathrm{I})\end{array}$ \\
\hline 11 & Due to this action [physical activity], we gain the shape and condition, then the form is increasing $(\mathrm{M}, \mathrm{l})$ \\
\hline 12 & There is physical activity with children, too. Games are active: squats, lift, and carry things (W, A) \\
\hline \multicolumn{2}{|r|}{ Benefits of PA } \\
\hline 13 & I don't keep at the back of my head that I go to the pool to be healthy (W, A) \\
\hline 14 & I move to make my mind work well $(\mathrm{W}, \mathrm{A})$ \\
\hline 15 & I just can be alone for a moment $(M, A)$ \\
\hline
\end{tabular}

\section{Optimal dose (volume) of PA}

17 Everyone is different, with individual needs (W, A)

18 Maybe there are some tests or something, but it all depends on age, gender, weight, perhaps morphology or confirmed hypertension (W, I)

19 I would like to walk about 30 minutes every day, the strength training or cardio three times per week, twice per week swimming in the pool to regenerate my

19 muscle, and everyday morning stretching $(\mathrm{W}, \mathrm{I})$

\section{Barriers to PA, social structural factors}

20 I used to be more enthusiastic, but due to overwork or accelerating lifestyle, all this accumulated in me and I just settled like a ship run aground (W, I)

21 There is always something more important at work or somewhere else. Or I just tend to find an excuse. As if I was a bit crazy (M, I)

22 I would love to practice Krav maga, but I was ashamed to go to training session, with so stiff and unstretched muscles (W, A)

23 I have heard once [from the trainer] 'Faster, my ladies, faster! The gym is not a dolphinarium!' (W, I)

$$
\text { Drivers, IEC }
$$

24 [You have to] change your approach. If I don't mobilize myself, nothing will happen ( $\mathrm{M}, \mathrm{I})$

25 There are plenty of ads within easy reach, or the ice rink is opening, or a new pool (W, A)

26 Just buy a gym membership from us and we will make you look better (W, A)

27 There are marches, runs, free classes, outdoor gyms available everywhere $(\mathrm{W}, \mathrm{I})$

28 Once a year a free visit [to a doctor] regarding healthy lifestyle is needed $(M, A)$

29 Home visits for elderly people may help them to learn something new, or to talk. These visits can be provided by a nurse with the consent of the persons

29 concerned $(\mathrm{W}, \mathrm{A})$

30 The chance of seeing a doctor quickly may be considered as a miracle $(M, A)$

31 I come to the doctor and he is telling me: we will talk when you lose the weight. Is it mean, I have to come to him in a half of the year? (W, A)

32 They [medical workers] are so bored or burned-out from their work, that they are only interested on drinking coffee with colleagues (W, I)

interpretation of health and illness. Secondly, it is possible that the group of persons/patients to which professionals refer, significantly differs from the study group, among others by age, health status or pain afflictions.

For lay people, the main benefits of PA were mental and spiritual well-being, as well as social, while professionals perceived PA in a strictly biomedical sense, which reinforces the thesis about travellers in parallel universes. This suggests that future IEC activities should focus on psycho-social benefits, but messages should be individualized, which means that there is no one-size-fits-all approach. It is essential to find a solution to the dilemma of how to communicate psycho-social benefits, while WHO recommendations are based and explained strictly on health, anatomical and physiological benefits.

The study participants had very different opinions about the type and optimal dose of PA, with both groups mentioning that this is an individual matter. Professionals adhered to the rule ' $3 \times 30 \times 130$ ' proposed in Poland in 1975 by Zbigniew Cendrowski [45]. Lay people were not aware of this old rule.

Attention is drawn to the fact that LP noticed the omnipresence of information about PA, as well as the availability of various facilities for PA in urban settings. However, they did not consider this as sufficient cues for PA. This shows that favourable social influences and environmental 
Table 2. Quotes by health professionals by theme

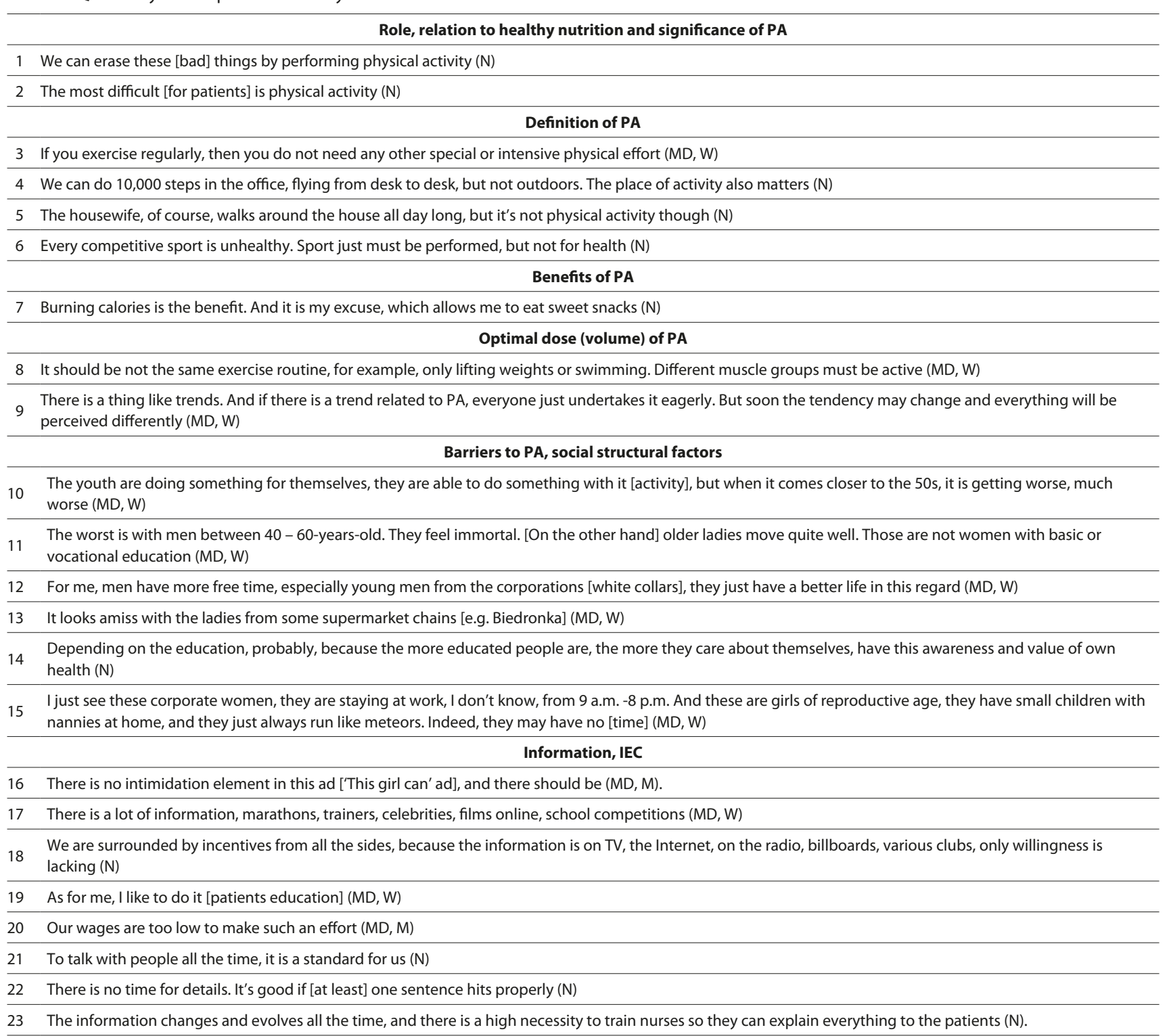

conditions, as well as knowledge about the benefits of PA, do not constitute a separate PA trigger. Discussions between participants regarding the driving forces, including IEC within PHC, lead to the conclusion that cues for action can be very personal and confirms other findings [46, 47]. These findings also support the thesis that the best explanation for PA determinants (causal relationship) is provided by the socio-ecological model of health, which combines the influence of biological, psychological, interpersonal, and those based on social or material factors [48].

During the interviews, none of the participants mentioned social media as a communication channel. There was a clear signal from both groups that expecting an effective IEC provided by PHC professionals seems to be rather difficult or even impossible in current circumstances. In addition, the attitude to the tone of the message was significantly different in both groups. A good example is analysis of the long-term advertising campaign 'This girl can', implemented in the UK in order to promote activity among women. Study participants were shown a film broadcast for the first time in October 2018, addressed to women with lower income. The film lasts 1:03 min, with comical situations, dynamic images, and lively, soaring music, without using words. In a positive light, it presents the physical struggles of women, with the main message summarized with the words: 'all of us (girls) are facing imperfections, but we are brave despite everything.' This advertisement was well-received in the UK, and induced the growth of PA [49]. In LP opinion, the film was very 'cool', convincing, motivating and fun, while HP found it too long, boring, 'did not contain the fear appeal, presenting women only as 'fluffy' (MD, M). Experience teaches us, that health professionals in Poland are accustomed to using fear appeals, not persuasion, although sometimes fear can be effective [50] albeit not desirable [51].

Study limitation. A limitation of this study was the relatively small number of participants, which usually adversely affects data saturation [52].This was due to time frame and financial constraints; for the same reason it was decided to conduct an FGI rather than an IDI. Only candidates aged 25-45 were selected for the study because it was important to explore the opinions of working people who are usually burdened with 
family responsibilities, which limits their freedom and free time, and may have an adverse effect on PA. The choice was also strengthened by the fact that this group is usually healthy and not burdened with chronic diseases which might cause movement difficulties. Farmers were excluded from the study because the nature of agricultural work is associated with specific occupational PA patterns, including heavy carrying and lifting [53], but with deficiencies of other types of PA [54]. Due to the unwillingness of professionals to participate in any study, the self-reported level of activity assessment for the sample of health profession was omitted. This could have an impact on the obtained results because many studies found a significant association between physicians' personal physical activity habits or fitness level, and patient counselling behaviours [55].

The results indicate that people living in the suburbs, within the administrative boundaries of cities, including those practicing regularly home gardening, do not differ from city centre ridents in terms of PA perception, its role and dose. It is likely that non-farmer village inhabitants have a similar perception of PA, which requires further research.

\section{CONCLUSIONS}

Based on findings from presented study groups, it is important to stress three points. Firstly, awareness of the beneficial effects of PA on health is widespread among lay people (no difference whether active or inactive), but health professionals did not recognise this fact. Additionally, for lay people, the main benefits of physical activity relate to psycho-social aspects while professionals stressed biomedical, disease-oriented ones. In the opinion of lay people, professionals working in $\mathrm{PHC}$ are not considered an important and desirable source of information or a driving force for PA. Professionals themselves also have many concerns and reservations about their educational role. Lay people valued positive and rewarding motivation to PA whereas professionals preferred fear-based messages. This leads to the conclusion that people and professionals are lithe above-mentioned 'travellers in parallel universe', which may hinder the effective IEC actions the PHC context.

Secondly, there is no well-established understanding of the definition of PA, resulting in conceptual chaos. Most lay people equate PA with exercises. Professionals also could not define PA, but saw alternatives to structured exercises. Similarly, the recommended and optimal dose (volume) of $\mathrm{PA}$ is altogether unclear and the WHO recommendation unknown.

Thirdly, in this study, no significant differences were found in the opinions of active and inactive people, which requires further research.

The study was conducted according to contract No. 2019/954310-3 202403586-3, between NIPH-NIH and WHO, under the Biennial Collaborative Agreement between the WHO/EURO and the Polish Ministry of Health 2018-19 - priority on NCDs: Increased access to interventions to prevent and manage non-communicable diseases and their risk factors. Support in developing interventions tackling NCDs in primary health care.

\section{Acknowledgements}

The authors express their thanks Romeu Mendes at the University of Porto, and to Stephen Whiting from the WHO Regional Office for Europe, who made constructive comments and recommendations which assisted in improving the readability and quality of the paper.

\section{REFERENCES}

1. Stevens M, Rees T, Coffee P, et al. A Social Identity Approach to Understanding and Promoting Physical Activity. Sports Med. 2017; 47(10): 1911-1918. https://doi.org/10.1007/s40279-017-0720-4

2. Rhodes RE, McEwan D, Rebar AL. Theories of physical activity behaviour change: A history and synthesis of approaches. Psychol Sport Exerc. 2019; 42: 100-109. https://doi.org/10.1016/j.psychsport.2018.11.010

3. Schwartz J, Rhodes R, Bredin SSD, et al. Effectiveness of Approaches to Increase Physical Activity Behavior to Prevent Chronic Disease in Adults: A Brief Commentary. J Clin Med. 2019; 8(3): 295. https://doi. org/10.3390/jcm8030295

4. Pate RR, Pratt M, Blair SN, et al. Physical activity and public health: recommendation from the Centers for Disease Control and Prevention and the American College of Sports Medicine. JAMA. 1995; 273(5): 402-407.

5. Pratt M, Perez LG, Goenka S, et al. Can population levels of physical activity be increased? Global evidence and experience. Prog Cardiovasc Dis. 2015; 57(4): 356-367. https://doi.org/10.1016/j.pcad.2014.09.002

6. Rutter H, Cavill N, Bauman A, et al. Systems approaches to global and national physical activity plans. Bull World Health Organ. 2019; 97: 162-165. http://dx.doi.org/10.2471/BLT.18.220533

7. World Health Organization. Global action plan on physical activity 2018-2030: more active people for a healthier world. WHO, Geneva 2018. https://apps.who.int/iris/bitstream/hand le/10665/272722/9789241514187-eng.pdf?ua=1 (access 2020.05.31).

8. World Health Organization. Physical activity strategy for the WHO European Region 2016-2025. WHO Regional Office for Europe, Copenhagen 2018. https://www.euro.who.int/__data/assets/pdf_ file/0014/311360/Physical-activity-strategy-2016-2025.pdf (access 2020.05.31).

9. Kahlmeier S, Wijnhoven TM, Alpiger P, et al. National physical activity recommendations: systematic overview and analysis of the situation in European countries. BMC Public Health. 2015; 12: 133. https://doi. org/10.1186/s12889-015-1412-3

10. Gelius P, Tcymbal A, Abu-Omar K, et al. Status and contents of physical activity recommendations in European Union countries: a systematic comparative analysis. BMJ Open. 2020; 10: e034045. http://dx.doi. org/10.1136/bmjopen-2019-034045

11. Tomik R, Dębska M, Gołaś A, et al. Krajowe rekomendacje prozdrowotnej aktywności fizycznej. Raport badawczo-analityczny. Ministerstwo Sportu i Turystyki, Akademia Wychowania Fizycznego im. Jerzego Kukuczki w Katowicach. Katowice, sierpień 2018. https:// www.gov.pl/web/sport/krajowe-rekomendacje-prozdrowotnejaktywnosci-fizycznej (access 2020.05.31), (in Polish).

12. Oja P, Titze S. Physical activity recommendations for public health: development and policy context. EPMA J. 2011; 2(3): 253-259. https:// doi.org/10.1007/s13167-011-0090-1.

13. Piercy KL, Troiano RP, Ballard RM, et al. The Physical Activity Guidelines for Americans. JAMA. 2018; 320(19): 2020-2028. https:// doi: 10.1001/jama.2018.14854

14. Knox ECL, Webb OJ, Esliger DW, et al. Using threshold messages to promote physical activity: implications for public perceptions of health effects. Eur J Public Health. 2014; 24(2): 195-199. https://doi. org/10.1093/eurpub/ckt060.

15. Dale LP, LeBlanc AG, Orr K, et al. Canadian physical activity guidelines for adults: are Canadians aware? Appl Physiol Nutr Metab. 2016; 41(9): 1008-1011. https://doi.org/10.1139/apnm-2016-0115

16. Nobles J, Thomas C, Banks Gross Z, et al. Let's Talk about Physical Activity: Understanding the Preferences of Under-Served Communities when Messaging Physical Activity Guidelines to the Public. Int J Environ Res Public Health. 2020; 17: 2782. https://doi.org/10.3390/ ijerph17082782

17. World Health Organization. Global recommendations on physical activity for health. WHO, Geneva 2010. https://apps.who.int/iris/ bitstream/handle/10665/44399/9789241599979_eng.pdf; jsessioni 
$\mathrm{d}=$ D108DDDB0353E68492258F591D9CC085? sequence $=1$ (access 2020.05.31).

18. UK Chief Medical Officers' Physical Activity Guidelines, 2019. https:// assets.publishing.service.gov.uk/government/uploads/system/uploads/ attachment_data/file/832868/uk-chief-medical-officers-physicalactivity-guidelines.pdf (access 2020.06.20).

19. U.S. Department of Health and Human Services. Physical Activity Guidelines for Americans, 2nd edition. 2018. Washington, DC: U.S https://health.gov/sites/default/files/2019-09/Physical_Activity_ Guidelines_2nd_edition.pdf (access 2020.05.31).

20. 2nd edition Australia's Physical Activity and Sedentary Behaviour Guidelines: Tips and Ideas for Adults (18-64 years). https://wwwl health.gov.au/internet/main/publishing.nsf/Content/ti-18-64years (access 2020.05.31).

21. Global action plan for the prevention and control of noncommunicable diseases 2013-2020. WHO. 2013; https://apps.who.int/iris/bitstream/ handle/10665/94384/9789241506236_eng.pdf;jsessionid=4F7BE53438 27969D8A0EE0A570AFF645? sequence $=1$ (access 2020.05.31).

22. Guthold R, Stevens GA, Riley LM, et al. Worldwide trends in insufficient physical activity from 2001 to 2016 : a pooled analysis of 358 populationbased surveys with 1,9 million participants. Lancet Glob Health. 2018 6(10): e1077-e1086. https://doi.org/10.1016/S2214-109X(18)30357-7

23. Ministerstwo Sportu i Turystyki. Badanie poziomu aktywności fizycznej społeczeństwa. https://www.msit.gov.pl/pl/sport/badania-i-analizy/ aktywnosc-fizyczna-spol/575,Aktywnosc-fizyczna-spoleczenstwa.html (access 2020.05.31), (in Polish).

24. Debska M, Mynarski W, Biernat E, et al. Compliance with physical activity health recommendations in members of non-governmental organizations promoting active lifestyle. Ann Agric Environ Med. 2019; 26(1): 109-113. https://doi.org/10.26444/aaem/94293

25. Macek P, Terek-Derszniak M, Zak M, et al. WHO recommendations on physical activity versus compliance rate within a specific urban population as assessed through IPAQ survey: a cross-sectional cohort study. BMJ Open. 2019; 9: e028334. http://dx.doi.org/10.1136/ bmjopen-2018-028334

26. Wen CP, Wai JPM, Tsai MK, et al. Minimum amount of physical activity for reduced mortality and extended life expectancy: A prospective cohort study. The Lancet. 2011 Oct 1; 378(9798): 1244-1253. https:// doi.org/10.1016/S0140-6736(11)60749-6

27. Ekelund U, Tarp J, Steene-Johannessen J, et al. Dose-response associations between accelerometry measured physical activity and sedentary time and all cause mortality: systematic review and harmonised meta-analysis. BMJ. 2019; 366: 4570. http://dx.doi. org/10.1136/bmj.14570

28. Klenk J, Kerse N. Every step you take. BMJ. 2019; 366: 15051. https:// doi.org/10.1136/bmj.15051

29. Ding D, Ramirez Varela A, Bauman AE, et al. Towards better evidenceinformed global action: lessons learnt from the Lancet series and recent developments in physical activity and public health. Br J Sports Med. 2020; 54: 462-468. http://dx.doi.org/10.1136/bjsports-2019-101001

30. Sygit KM, Sygit M, Wojtyła-Buciora P, et al. Physical activity as an important element in organizing and managing the lifestyle of populations in urban and rural environments. Ann Agric Environ Med. 2019; 26(1): 8-12. https://doi.org/10.26444/aaem/99177

31. Vaara JP, Vasankari T, Koski HJ, et al. Awareness and Knowledge of Physical Activity Recommendations in Young Adult Men. Front Public Health. 2019; 7: 310. https://doi.org/10.3389/fpubh.2019.00310

32. Segar M, Taber JM, Patrick H, et al. Rethinking physical activity communication: using focus groups to understand women's goals, values, and beliefs to improve public health. BMC Public Health. 2017; 462. https://doi.org/10.1186/s12889-017-4361-1

33. Piercy KL, Bevington F, Vaux-Bjerke A, et al. Understanding Contemplators' Knowledge and Awareness of the Physical Activity Guidelines. J Phys Act Health. 2020; 4: 404-411. https://doi.org/10.1123/ jpah.2019-0393

34. Rhodes RE, Rebar AL. Conceptualizing and Defining the Intention Construct for Future Physical Activity Research. Exerc Sport Sci Rev. 2017; 45(4): 209-216. https://doi.org/10.1249/JES.0000000000000127

35. Cusatisa R, Garbarski D. Which activities count? Using experimental data to understand conceptualizations of physical activity. SSM Popul Health. 2018; 6: 286-294. https://doi.org/10.1016/j.ssmph.2018.10.002
36. Williams V, Boylan A, Nunan D. Critical appraisal of qualitative research: necessity, partialities and the issue of bias. BMJ Evid Based Med. 2020; 25: 9-11. http://dx.doi.org/10.1136/bmjebm-2018-111132

37. Carter DD, Robinson K, Forbes J, et al. Experiences of mobile health in promoting physical activity: A qualitative systematic review and meta-ethnography. PLoS One. 2018; 13(12): e0208759. https://dx.plos. org/10.1371/journal.pone.0141803

38. Malterud K. Qualitative research: standards, challenges, and guidelines. Lancet 2001; 358(9280): 483-488. https://doi.org/10.1016/S01406736(01)05627-6

39. Caspersen CJ, Powell KE, Christenson GM. Physical activity, exercise, and physical fitness: definitions and distinctions for health-related research. Public Health Rep. 1985; 100(2): 126-131.

40. Zourikian N, Jarock C, Mulder K. Physical Activity, Exercise and Sports. A Guide for Families. Canadian Hemophilia Society. 2010, chapter 12.

41. Dasso NA. How is Exercise Different from Physical Activity? A Concept Analysis. Nurs Forum. 2019; 54: 45-52. https://doi.org/10.1111/ nuf.12296

42. Tudor-Locke C, Henderson CA, Wilcox S, et al. In their own voices: definitions and interpretations of physical activity. Womens Health Issues. 2003; 13(5): 194-9. https://doi.org/10.1016/ S1049-3867(03)00038-0

43. Johnson I, Tillgren P, Hagströmer M. Understanding and interpreting the concept of physical activity - a focus group study among Swedish women. Scand J Public Health. 2009 Jan; 37(1): 20-7. https://doi. org/10.1177/1403494808099963

44. Godino JG, Watkinson C, Corder K, et al. Awareness of physical activity in healthy middle-aged adults: a cross-sectional study of associations with sociodemographic, biological, behavioural, and psychological factors. BMC Public Health. 2014; 14: 421. https://doi.org/10.1186/14712458-14-421

45. Cendrowski Z. Nowa podstawa programowa wychowania fizycznego i edukacji zdrowotnej na tle problemów cywilizacyjnych i zdrowotnych. Kult Fiz. 2009; 5/6: 1-13. (in Polish).

46. Sooknarine-Rajpatty J, Auyeung AB, Doyl F. A Systematic Review Protocol of the Barriers to Both Physical Activity and Obesity Counselling in the Secondary Care Setting as Reported by Healthcare Providers. Int J Environ Res Public Health. 2020; 17: 1195. https://doi. org/10.3390/ijerph17041195

47. Herazo-Beltrán Y, Pinillos Y, Vidarte J, et al. Predictors of perceived barriers to physical activity in the general adult population: a crosssectional study. Braz J Phys Ther. 2017; 21(1): 44-50. https://doi. org/10.1016/j.bjpt.2016.04.003

48. Bauman A, Reis R, Sallis J, et al. Correlates of physical activity: why are some people physically active and others not? Lancet 2012; 380(9838): 258-271. https://doi.org/10.1016/S0140-6736(12)60735-1

49. Kemp N. Case study: How ,This girl can'got 1.6 million women exercising. Campaign May 18, 2016. https://www.campaignlive.co.uk/ article/case-study-this-girl-can-16-million-women-exercising/1394836 (access 2020.05.31).

50. Tannenbaum MB, Hepler J, Zimmerman RS, et al. Appealing to fear: A Meta-Analysis of Fear Appeal Effectiveness and Theories. Psychol Bull. 2015; 141(6): 1178-1204. https://doi.org/10.1037/a0039729

51. Brown TC, Fry MD, Moore EWG. A Motivational Climate Intervention and Exercise-Related Outcomes: A Longitudinal Perspective. Motiv Sci. 2017; 3(4): 337-353. https://doi.org/10.1037/mot0000059

52. Moser A, Korstjens I. Series: Practical guidance to qualitative research. Part 3: Sampling, data collection and analysis, Eur J Gen Pract. 2018; 24(1): 9-18. https://doi.org/10.1080/13814788.2017.1375091

53. Racine EF, Laditka SB, Dmochowski J, et al. Farming Activities and Carrying and Lifting: The Agricultural Health Study. J Phys Act Health. 2012; 9(1): 39-47. https://doi.org/10.1123/jpah.9.1.39

54. Biernat E, Piątkowska M, Mynarski W. Prevalence and socioeconomic determinants of leisure time physical activity among Polish farmers. Ann Agric Environ Med. 2018; 25(1): 151-156. https://doi.org/10.26444/ aaem/75927

55. Lobelo F, Garcia de Quevedo I. The Evidence in Support of Physicians and Health Care Providers as Physical Activity Role Models. Am J Lifestyle Med. 2016; 10(1): 36-52. https://doi.org/10.1177/1559827613520120 